\title{
Reflexões sobre a prática do residente terapeuta ocupacional na estratégia saúde da família no município de São Carlos
}

\section{About the therapist occupational Residence practice at family healthcare strategy in São Carlos}

\author{
Flávia Manho' ${ }^{1}$ Léa Beatriz Teixeira Soares ${ }^{2}$, Stella Maris Nicolau ${ }^{3}$
}

http://dx.doi.org/10.11606/issn.2238-6149.v24i3p233-41

\begin{abstract}
Manho F, Soares LBT, Nicolau SM. Reflexões sobre a prática do residente terapeuta ocupacional na Estratégia Saúde da Família no município de São Carlos. Rev Ter Ocup Univ São Paulo. 2013 set.-dez.;24(3):233-41.
\end{abstract}

RESUMO: O olhar dos residentes egressos de Terapia Ocupacional sobre suas práticas na Residência Multiprofissional em Saúde da Família e Comunidade da UFSCar foi o objetivo deste estudo. Durante o programa de pós-graduação "lato sensu", de ensino em serviço, os residentes desenvolvem competências de cuidado individual e coletivo, gestão, educação permanente e pesquisa, na lógica do apoio matricial, inseridos em Unidades de Saúde da Família do município. Responderam a um questionário on-line, sete dos oito residentes formados de 2007 a 2011. O material empírico foi agrupado em blocos a partir de um entendimento da hermenêutica dialética em diálogo com o referencial teórico e o projeto pedagógico da residência. Embora com diferenças, todos os residentes puderam reconhecer, de forma ampliada, as práticas e os preceitos da Estratégia Saúde da Família. Nos relatos, associaram o cuidado individual e coletivo ao núcleo de saber da Terapia Ocupacional, e associaram as ações coletivas, de gestão e de educação permanente, ao campo de saber da Saúde Coletiva. Os egressos reconheceram a residência como fundamental para sua formação pessoal e profissional.

DESCRITORES: Terapia ocupacional; Saúde Pública; Saúde da família; Internato não médico; Ocupações relacionadas com saúde/ educação; Residência multiprofissional em Saúde.
Manho F, Soares LBT, Nicolau SM. About the therapist occupational Residence practice at family healthcare strategy in São Carlos. . Rev Ter Ocup Univ São Paulo. 2013 set.dez:;24(3):233-41.

\begin{abstract}
This study, based on dialectical hermeneutics, investigated the view of occupational therapists posgraduates at University of São Carlos about their practices. During the residence, they worked in a Unit of Family Healthcare in which they are inserted in a matrix organization model and they had permanent education and research based in practice, learning about management of health services, individual and collective care. Seven graduates, who concluded the residence between 2007 and 2011, answered an on-line questionnaire. This material was grouped in accordance to comprehensive and critical social reality knowledge based in the pedagogic project and residence theory. Although each student has had different view, everyone experienced and recognized, generally, the practice according to Family Health Strategy precepts: comprehensive health care, interdisciplinary, intersectionality, networking, social control, co-responsibility, autonomy and protagonism. Moreover, the answers demonstrated an association between care (individual and collective) to occupational therapy center of knowledge, and groups management and permanent education were associated to community health. In conclusion, the posgraduates recognized the residence as a fundamental experience to their personal and professional formation.
\end{abstract}

KEYWORDS: Occupational therapy; Public health; Family health, Internship, nonmedical; Allied health occupations/ education; Multidisciplinary Residency Program.

Trabalho de conclusão de curso apresentado ao Programa de Residência Multiprofissional em Saúde da Família e Comunidade da Universidade Federal de São Carlos.

1. Terapeuta Ocupacional Especialista em Saúde da Família e Comunidade pela Universidade Federal de São Carlos, São Carlos, SP, Brasil. flavia.manho@gmail.com.

2. Orientadora, Professora Associada, Docente Voluntária da Universidade Federal de São Carlos, São Carlos, SP, Brasil. leasoares57@, gmail.com.

3. Co-orientadora, Professora Adjunta, Tutora da Residência Multiprofissional em Saúde da Família e Comunidade, Universidade Federal de São Carlos, São Carlos, SP, Brasil. stellanicolau@uol.com.br.

Endereço para correspondência: Flávia Manho. Rua Hélio Steffen, 34, Vila Romão, Salto, SP. CEP: 13321-070. E-mail: flavia.manho@, gmail.com. 


\section{INTRODUÇÃO}

Estratégia Saúde da Família - ESF,
principal modelo organizador da Atenção
Básica do país, caracteriza-se pelo cuidado integral e longitudinal em saúde com foco na unidade familiar. Por meio de ações individuais e coletivas busca a promoção, prevenção, proteção e reabilitação para manutenção da saúde ${ }^{1}$.

Adota como principais diretrizes: o acesso universal; a adscrição do território e da clientela; o trabalho em redes intra e intersetoriais; o acolhimento e estabelecimento de vínculos com os usuários. Integra ainda em suas diretrizes o papel de coordenação do cuidado. Visa a resolutividade da maior parte dos problemas de saúde da população ${ }^{1}$, com a possibilidade de identificação dos riscos e de intervenção em ação mais próxima da vida cotidiana da população e de grupos mais vulneráveis. A ESF requer dos profissionais um perfil generalista, o trabalho em equipe e a inclusão do agente comunitário de saúde².

Neste contexto o território é compreendido como espaço delimitado geograficamente, construído historicamente e com relações socioeconômicas e culturais transformadas e criadas constantemente ${ }^{3}$. Nele, as intervenções devem ser norteadas pelo respeito á cultura e cidadania. A ação técnica implica no conhecimento do outro e na apreensão das identidades singulares e coletivas, das culturas locais, e das formas de linguagem e da possibilidade de comunicação presentes no território e no repertório dos usuários. Além disso, o desenvolvimento das ações deve partir das necessidades da pessoa, do grupo, da comunidade ${ }^{3}$.

A ESF preconiza o trabalho em equipe interdisciplinar, denominada de equipe de referência, formada por agente comunitário de saúde - ACS, auxiliar de enfermagem, enfermeiro e médico, podendo também incluir uma equipe de saúde bucal, constituída de auxiliar de consultório odontológico e dentista, como ocorre no município de São Carlos.

Para ampliar e apoiar as possibilidades de resposta das equipes de Saúde da Família, é proposto o Apoio Matricial, que consiste na articulação de diversas experiências e saberes, em espaços de ampla comunicação entre as equipes de referência e seus apoiadores). Pode funcionar de três formas: condução conjunta do caso com profissionais da referência; troca de conhecimentos e orientações de casos com referência e apoiadores; realização do atendimento direto pelo apoiador, se necessário devido a sua especialidade, em corresponsabilidade com a referência ${ }^{5}$.
Atualmente o Ministério da Saúde - MS - também preconiza o Apoio Institucional, que tem como objetivo a mudança nas organizações, tomando como matéria-prima os problemas e tensões do cotidiano. O apoiador deve ajudar as equipes a colocar o próprio trabalho em análise e a produzir alternativas para o enfrentamento conjunto dos desafios. Opera como disparador de processos que propiciem o suporte ao movimento de mudança deflagrado por coletivos, buscando fortalecê-los no próprio exercício da produção de novos sujeitos ${ }^{4}$.

De acordo com a Constituição Federal, a formação de recursos humanos em saúde é ordenada pelo Sistema Único de Saúde (SUS). Em 1999, o Departamento de Atenção Básica (MS) articulou-se a atores do Movimento Sanitário, para a criação de programas de residência com foco na Saúde da Família. Este modelo preservou as especialidades de cada profissão envolvida e também criou uma área comum, especialmente vinculada ao pensamento da tradicional Saúde Pública, acrescida de valores como promoção da saúde, integralidade da atenção e acolhimento ${ }^{6}$.

As Residências Multiprofissionais em Saúde da Família se apresentam em diversos formatos, mas mantêm a perspectiva de incorporar integradamente as profissões da saúde ${ }^{6}$ e a formação do núcleo e do campo de saberes. $\mathrm{O}$ núcleo corresponde à identidade de uma área de saber e de prática profissional, enquanto o campo diz respeito a um espaço de limites imprecisos onde cada disciplina ou profissão busca, em outras, o apoio para cumprir suas tarefas teóricas e práticas ${ }^{7}$.

O programa de Residência Multiprofissional em Saúde da Família e Comunidade - PRMSFC - da UFSCar constitui-se enquanto pós-graduação "lato sensu", que se utiliza da abordagem construtivista, fundamentada na aprendizagem significativa de adultos, com metodologias ativas de ensino-aprendizagem.

Os residentes atuam com base nas competências de cuidado (individual e coletivo), gestão, educação e pesquisa, inserindo-se nas Unidades de Saúde da Família - USF, na lógica do Apoio Matricial, o que contribui para formação profissional dos residentes e também para a potencialização dos profissionais dos serviços, para construção de estratégias de ampliação da qualidade e eficiência dos serviços de saúde, para o enfrentamento das necessidades de saúde da população ${ }^{8}$.

"Os diversos lugares que construíram programas de Residência Multiprofissional em Saúde, o fizeram procurando aproximar o ensino da gestão, o que por si só já se constitui em inegável inovação na formulação de políticas para formação de trabalhadores do e para o SUS" (p.13) ${ }^{6}$ 
As atividades do residente incluem atividades teóricas, tutoria de campo (nos cenários da prática), tutoria de área (específica da profissão), preceptorias, reunião de residentes e plantões em outros serviços da Rede Escola. No segundo ano, a presença do residente na(s) USF é reduzida pelo acréscimo dos estágios (eletivo e especializado) e de projeto na comunidade.

O programa contempla dez profissões da saúde (Educação Física, Enfermagem, Farmácia, Fisioterapia, Fonoaudiologia, Nutrição, Odontologia, Psicologia, Serviço Social e Terapia Ocupacional), com diversidade na composição e oscilação de vagas decorrente de um lado do orçamento do Ministério da Saúde e de outros da rede local, perfil sociodemográfico, epidemiológico do município ${ }^{8} \mathrm{e}$ quadro de pessoal na saúde.

Há dois arranjos interdisciplinares para os residentes: um arranjo em que os residentes dentista e enfermeiro atuam em uma USF; outro, denominado equipe matricial, em que as demais especialidades dividem mesma carga horária em duas USF(s) que recebem os residentes.

Este estudo teve como objetivo refletir sobre a prática e inserção dos residentes concluintes de Terapia Ocupacional (2007 a 2011) nas USF do Município de São Carlos, a partir de seus olhares. Buscou compreender questões referentes ao núcleo e campo de saberes, aos eixos de competência propostos pela residência e às repercussões desta vivência para os participantes.

\section{PROCEDIMENTOS METODOLÓGICOS}

A pesquisa qualitativa* teve como participantes terapeutas ocupacionais que cursaram e concluíram a residência de 2007 a 2011. No período da coleta os participantes desenvolviam outras ocupações e não residiam no município de São Carlos, diante disso optou-se pela coleta on-line, o que reduziu o tempo de deslocamento ou ajuste de agenda presencial entre os atores.

Nicolaci-Da-Costa et al. ${ }^{9}$ desenvolveram estudo para comparação da entrevista presencial e on-line e constataram que a eficácia é a mesma, apresentando ainda vantagens na coleta de dados on-line como redução de custos e de tempo e maior objetividade, o que não é sinônimo de superficialidade.

Em março de 2012, foi realizado convite para pesquisa por meio de contato telefônico, seguida de envio de e-mail para a continuidade da comunicação. No período de abril a junho o roteiro semi-estrutrado foi enviado pelo pesquisador e respondido pelos participantes. Quando necessário, foram realizados novos contatos para esclarecimentos ou aprofundamento dos relatos.

Os discursos foram compreendidos com base na hermenêutica dialética, que define a compreensão como a possibilidade de interpretar, estabelecer relações e extrair conclusões em todas as direções. Compreender não é um procedimento mecânico e tecnicamente fechado; nada do que se interpreta pode ser entendido de uma só vez e de uma vez por todas. O discurso sempre expressa um saber partilhado com outros e marcado pela tradição, pela cultura e pela conjuntura ${ }^{10}$. Assim,

"O ato do entendimento, mais que um desvendamento da verdade do objeto, é a revelação do que o 'outro' (o 'tu') coloca como verdade" ( p.333)

Enquanto a hermenêutica busca essencialmente a compreensão, a dialética estabelece uma atitude crítica. Dessa forma, a associação dessas duas abordagens possibilitou um processo compreensivo e crítico da realidade social; buscou, nas suas especificidades históricas, a cumplicidade com seu tempo e, nas diferenciações internas, sua contribuição à vida, ao conhecimento e às transformações ${ }^{10}$.

O material empírico foi agrupado em blocos semânticos para uma compreensão crítica em diálogo com materiais teóricos que embasaram a residência. Foram utilizados nomes fictícios escolhidos pelos próprios entrevistados ou pela pesquisadora.

\section{RESULTADOS E DISCUSSÃO}

O PRMSFC teve quatorze ingressantes de Terapia Ocupacional entre 2007 e 2011, dos quais oito concluíram o programa. As desistências decorreram de contratação para emprego fixo (a residência tem duração de dois anos). Sete concluintes responderam à entrevista e um justificou a recusa. A receptividade dos participantes possibilitou a inferência da mobilização de sentimentos desta vivência profissional.

\section{Residência como experimento: aprender e amadurecer em formação}

A metodologia construtivista adotada pelo PRMSFC valorizou o aprendizado a partir de vivências e experiências significativas para cada residente. $\mathrm{O}$ despreparo inicial para lidar com as variadas demandas exigiu dos

\footnotetext{
*Pesquisa aprovada pelo Comitê de Ética da Universidade Federal de São Carlos, parecer número 196.250.
} 
residentes maior esforço e disposição, em um momento de apoio e construção conjunta de referenciais utilizados em sua formação.

No segundo ano, a maturidade da intervenção e da postura profissional se relacionou com a maior segurança a respeito da profissão e dos manejos, o fortalecimento do vínculo com as equipes e a vivência de oportunidades proporcionadas pelo PRMSFC.

É possível inferir que no primeiro ano, o residente, geralmente recém-formado, focou sua prática no cuidado individual, muitas vezes como um 'especialista' no território. A maturidade adquirida no segundo ano possibilitou a ampliação da prática para o cuidado coletivo, gestão, educação e ações de articulação com a Rede Escola, agora com mais recursos para atuar na lógica do Apoio.

$\mathrm{Na}$ medida em que o estágio especializado, o estágio eletivo e o projeto na comunidade foram inseridos os residentes priorizaram ações e qualificaram o cuidado na USF.

"Se no primeiro ano foram realizadas diferentes experimentações, foi no segundo que algumas delas se mostraram sustentáveis e outras tiveram seu curso natural de encerramento." (Ana)

\section{Núcleo x Campo de saberes}

Dois concluintes apontaram que as práticas desenvolvidas no núcleo e no campo de saberes foram indissociáveis

\begin{abstract}
"Talvez, todas as ações desenvolvidas possam ser entendidas como dentro do campo da Saúde Coletiva, pois mesmo aquelas que realizei como terapeuta ocupacional, no cenário em que eram desenvolvidas, foram norteadas pelos principios deste campo. Ou seja, quando intervinha em um determinado caso, por exemplo, ali estava incorporada a lógica do acompanhamento longitudinal, da corresponsabilização, o princípio da integralidade, a perspectiva da promoção à saúde, dentre outros" (Ana).
\end{abstract}

Campos $^{7}$ discute que os conceitos de núcleo e campo de saberes combinam graus de polivalência com certo nível necessário e inevitável de especialização. Em um extremo, contextos tradicionais e bem hierarquizados tendem à burocratização do trabalho e à responsabilização restrita a sua própria área técnica; em outro extremo, em experiências mais radicais de horizontalização, é comum igualar-se de modo artificial todos os profissionais, em que todos fariam tudo e ninguém pessoalmente seria responsável por nada, pois o projeto terapêutico seria coletivo. Neste extremo, abandona-se a identidade profissional, são realizadas ações de integração social ou mobilização em prol do coletivo, com poucos procedimentos típicos das especialidades, mesmo quando necessários.

À luz destes conceitos, o terapeuta ocupacional intervém no campo para o qual também disponibiliza suas especificidades nucleares ${ }^{11}$. No entanto, apesar dos relatos anteriores, a descrição de algumas ações gerou o questionamento a respeito de como tais especificidades intervieram e foram disponibilizadas no campo durante $o$ PRMSFC.

Foram observadas associações entre o cuidado (individual e coletivo) ao núcleo de saber da Terapia Ocupacional, enquanto as ações coletivas, de gestão e de educação permanente* foram relacionadas ao campo da Saúde Coletiva.

Tanto as práticas do núcleo quanto do campo de saberes foram influenciadas pelo contexto de inserção, práticas, recursos prévios e disponíveis para cada residente, além de interesses, habilidades pessoais e dinamicidade dos territórios.

\section{Núcleo da Terapia Ocupacional}

"Dificuldades acerca da compreensão da prática da Terapia Ocupacional foram encontradas em todos os campos, mas acredito que fazem parte da nossa luta diária em divulgar nossa atuação e conquistar nosso espaço dentro da clínica e do cuidado". (Carolina)

Diante disso, a fim de ampliar ações específicas da Terapia Ocupacional, os entrevistados desenvolveram atividades de educação para as equipes, bem como a experimentação de recursos terapêuticos em momentos de reunião e de Educação Permanente, visitas domiciliares e grupos, com posteriores reflexões a respeito da profissão e de seus instrumentos.

Neste contexto destaca-se o desconhecimento e a falta de clareza de residentes e PRMSFC a respeito do núcleo de saber da Terapia Ocupacional. Maria observou que houve, em sua formação, poucos espaços para aprofundamento de questões da profissão, o que a levou a

\footnotetext{
* Educação Permanente: pressupõe processo pedagógico que contemple desde a aquisição/atualização de conhecimentos e habilidades até o aprendizado que parte dos problemas e desafios enfrentados no processo de trabalho. O planejamento educativo ascendente possibilita a construção de estratégias contextualizadas que promovam o diálogo entre as políticas gerais e a singularidade dos lugares e das pessoas ${ }^{4}$.
} 
buscar supervisão e grupos de estudos ao sair do programa.

"Acredito que o cuidado individual, com uma maior apropriação do núcleo da Terapia Ocupacional, deixou a desejar - poucos espaços para aprofundamento dessas questões. Atualmente estou no campo da assistência direta e sinto uma maior necessidade de apropriação no núcleo. Tenho buscado grupos de estudo em Terapia Ocupacional, supervisões etc" (Maria).

O apoio da Terapia Ocupacional foi solicitado nas ações de promoção de saúde, com pessoas de todas as faixas etárias, e no cuidado das seguintes demandas e problemáticas: dificuldade de aprendizagem; dificuldades de inserção social e no trabalho por deficiência ou sofrimento mental; dependência química; doenças relacionadas ao trabalho; doenças crônicas e incapacitantes; dores generalizadas e situações de risco pessoal e social.

Os concluintes relataram que ao ampliar o olhar às demandas do cuidado individual a alguns usuários foi impulsionada a busca de espaços na rede intra e intersetorial em Saúde Mental e alternativas de trabalho e renda como a Economia Solidária. Este cuidado foi desenvolvido de forma individual ou em conjunto com outros profissionais (residentes ou da equipe local), em visita domiciliar (urbana ou rural), centro comunitário, biblioteca ou escolas.

O trabalho em conjunto com a equipe de referência e, se necessário, com a rede de serviços do município, o protagonismo e a autonomia dos usuários foram priorizados pelos residentes.

"A metodologia ativa de ensino-aprendizagem cria potenciais em que os profissionais são estimulados a serem mais criativos em sua atuação e os usuários ganham com novas possibilidades de serem cuidados" (Helena)

Outra estratégia utilizada foi o matriciamento em discussões de casos, em busca da construção conjunta de Projetos Terapêuticos Singulares, se possível, juntamente com os usuários. Nas reuniões de equipe também se deu a Educação Permanente com temas como: o que é Terapia Ocupacional, dependência química e manejo de grupo. $\mathrm{O}$ olhar da Terapia Ocupacional trouxe novas perspectivas na compreensão dos casos, na apreensão das dinâmicas do território e dos processos de trabalho das equipes.

A Educação Permanente também ocorreu em outros espaços, como recorda Carolina:

"grupo de puericultura: um atendimento coletivo realizado pela equipe multiprofissional, em ação simultânea de cuidado e matriciamento dos profissionais".
Algumas atividades coletivas, relacionadas principalmente ao uso de atividades, foram subsidiadas pelo saber da Terapia Ocupacional, como grupo de fios e grupo de linguagens artísticas que visavam ao convívio social.

\section{Campo da Saúde Coletiva}

As práticas de cuidado coletivo foram focadas principalmente na prevenção de doença e promoção de saúde. Foram referidos grupos com: mulheres; gestantes; portadores de hipertensão e, ou diabetes; crianças em vulnerabilidade social; adolescentes na escola (sexualidade); grupos de: artesanato; caminhada; saúde do trabalhador; resgate das histórias do bairro; linguagens artísticas com crianças e adolescentes. Em muitos casos, os grupos foram coordenados por residente(s) e membro(s) da referência.

Os residentes contribuíram na construção de "dias temáticos" às linhas de cuidado, citaram: festas típicas, "dias da beleza", campanha de vacinação, férias com as crianças, "bingo da saúde", ações com professores nas escolas, reuniões com a comunidade, dentre outras com foco na promoção de saúde e/ou fortalecimento da participação popular/controle social, e o atendimento às necessidades específicas do território.

"O modelo pedagógico adotado, apesar de muito trabalhoso, foi muito mais coerente com a proposta de matriciamento e com a produção de novas formas de saúde”. (Márcia)

A comunicação intrassetorial foi desenvolvida com Unidades Básicas de Saúde, Centros de Atenção Psicossocial (CAPS II e ad), Centro Médico de Especialidades, SAMU e Hospital Universitário. Quatro residentes participaram efetivamente de Conselhos Gestores de Saúde.

Dois residentes aproximaram-se intensamente da Saúde Mental, devido às demandas das unidades e interesse pessoal. Participaram da construção e reativação de espaços de discussão e planejamento: Encontro de Saúde Mental, Fórum de Saúde Mental, Conferência de Saúde Mental e minicurso "Saúde Mental na Atenção Básica" em 2009 e 2010.

Para além da rede de saúde, foi estabelecida parceria intersetorial com os Centros Regionais de Assistência Social, escolas, diferentes departamentos da UFSCar e serviços de proteção à criança e ao adolescente vinculados à programas de medidas socioeducativas. 


\section{Áreas de competência}

O PRMSFC propôs o desenvolvimento de competências em cuidado - individual e coletivo, educação, gestão e pesquisa.

Os entrevistados, exceto dois, acreditam que foi possível desenvolver uma base em todas áreas de competência, embora apresentem ressalvas e necessidade de seu aperfeiçoamento.

A competência gestão, ao mesmo tempo em que foi considerada bastante potente nos espaços intra equipe e de controle social, apresentou-se quase nula no referente à articulação de rede e macrogestão. Maria observou que esta também foi pouco aprofundada em sua formação prévia e, assim como Carolina, compreendeu que na residência pôde aproximar-se do trabalho em equipe e da reorganização dos processos de trabalho, com participação em espaços formais e informais de gestão. Os concluintes apontaram que as experiências de gestão se restringiram ao âmbito das USF inseridas, não sendo explorados outros recursos de organização e gestão de redes em saúde.

Carlos complementou sobre a fragilidade da gestão como reflexo de três realidades:

"A primeira, pelo fato de a Academia ter iniciado uma aproximação com a realidade, com a rede de saúde do municipio; a segunda, pela sua falta de conhecimentos e experiências sobre o tema; e a terceira, pelo tema do planejamento e gestão ser pouco desenvolvido no cotidiano das equipes de saúde."

Metade dos concluintes participou efetivamente de Conselhos Gestores de Saúde, sendo um caso relatado em periódico nacional.

Já a área da pesquisa, não sendo colocada como prioritária para alguns, gerou desgastes e frustrações. A não prioridade e a dificuldade para seu desenvolvimento podem estar relacionadas à reduzida carga horária disponível para tal. Duas residentes relataram o desenvolvimento de suas pesquisas a respeito de práticas nas USF em que estavam inseridas.

Por fim, na área do cuidado, um entrevistado apontou a dificuldade decorrente do despreparo inicial, enquanto outro identificou o parco suporte do Programa em relação ao núcleo de saber, para o seu respectivo aprofundamento.

Na Atenção Básica, de acordo com Soares ${ }^{12}$ (p.7):

"A Terapia Ocupacional, por seu núcleo de conhecimento, tem atuado na gestão do trabalho em equipe bem como na capacitação de profissionais para os desafios deste trabalho, no planejamento e na execução do cuidado junto às pessoas e coletividades no território, no domicílio e nos equipamentos sociais. $O$ foco é sua autonomia e qualidade de vida, especialmente na reabilitação física, saúde mental e na qualificação das ações grupais e educativas."

\section{Apoio}

Os residentes consideraram que desenvolveram tanto ações direcionadas pelo Apoio Matricial quanto pelo Institucional - com maior intensidade o matricial - e que os dois, muitas vezes, se misturavam durante as intervenções.

"Acho que realizei ambos. Mais intensamente o apoio matricial, através das discussões de casos e capacitações e que permitiram, mesmo num ritmo lento, a possibilidade de transformar o olhar que a equipe tinh a frente a determinadas populações atendidas. Ao mesmo tempo, éramos corriqueiramente atravessados por questões do trabalho que dificultavam o bom andamento de ações programadas, ou uma falta de entendimento das novas diretrizes do SUS e que, a partir daí, auxiliávamos as USF e, se necessário outros serviços envolvidos, a pensar estratégias e novas possibilidades de intervenção frente a cada situação". (Helena)

As ações de matriciamento abarcaram a retaguarda assistencial e o suporte técnico-pedagógico, tanto em momentos formais de reunião quanto no cotidiano das USF. Cinco dos residentes referiram ter desenvolvido o Apoio Institucional, um relatou tentativa mal sucedida e dois apontaram falta de clareza conceitual.

"Não sei se domino com clareza o conceito de apoio institucional para fazer essa distinção. $O$ apoio institucional não foi objeto de nosso estudo e execução (pelo menos consciente) durante o meu tempo na RMSFC. Talvez ações próximas ao apoio institucional tenham sido aquelas de apoio às equipes na organização dos processos de trabalho e nas articulações com outros serviços rede." (Ana)

Observaram que foram desenvolvidas ações similares a Apoio Institucional, relativas ao apoio na organização dos processos de trabalho das equipes, nas articulações com outros serviços da rede, na reorganização das reuniões de equipe e na reestruturação do cuidado.

A concepção frágil sobre Apoio Institucional pode estar relacionada à sua incorporação recente e o próprio PRMSFC, apesar de estimular práticas semelhantes, pouco se apropriou do mesmo.

A área de competência gestão é dividida em duas subáreas, uma referente à gestão do cuidado à saúde e outra, 
ao processo de trabalho. Nesta encontram-se: a promoção e/ou participação em espaços de reflexão coletiva sobre o processo de trabalho e planos de ação que favorecem as potencialidades em ambiente solidário, compromissados com a transformação de práticas e cultura organizacional, no sentido da defesa do direito à saúde e da cidadania.

Cabe destaque o apontamento a respeito da atenção necessária do residente para diferenciar o "fazer junto" e "fazer por"

"Entendo o matriciamento como um fazer junto, a fim de potencializar a equipe no cuidado da população de sua área de abrangência. Acredito que em alguns momentos isso foi possivel tal como na elaboração junto com os ACS de um grupo na comunidade (...); nos momentos em que discutimos alguns temas para qualificação do cuidado (...), fazendo atendimentos compartilhados com médicos e enfermeiras, visitas domiciliares conjuntas etc. (...)

Vejo, porém, que em outros momentos o 'fazer junto'se tornou um 'fazer por'... e ai vejo que o matriciamento não aconteceu (casos em que a equipe não lidava e que acabávamos lidando sem conseguir compartilhar o cuidado - casos que não se tornaram significativos para o cuidado da equipe, o que tende a 'se perder', tendo em vista a rotatividade do residente).(Maria)"

Os residentes de Terapia Ocupacional, inseridos em duas Unidades, puderam identificar que as oportunidades oferecidas por cada campo exigiam atenção e respostas singulares, com flexibilidade e posicionamentos de acordo com cada situação.

"Tinha de exercitar bastante o momento certo de ceder e de manter determinados posicionamentos; nem sempre acertava, mas foi bastante rico para minha vida profissional". (Márcia)

Os residentes ainda citaram outros fatores intervenientes em suas possibilidades de ação na lógica do Apoio:

- Inserção profissional;

- Inserção pessoal, relacionada ao campo das relações humanas, das afetividades, por vezes mascaradas por discursos e posturas corporativistas, disputas de projetos e conflitos de interesses para a saúde local;

- Compreensão e aceitação da equipe a respeito do matriciamento, desfavorecendo-o e pressionando o residente para uma prática restrita ao consultório, como espaço ambulatorial ou favorecendo-o para o matriciamento;

- Resistência de equipes a respeito do PRMSFC;
- Processos de trabalho de equipes mais antigas, com resistências à mudança e organização mais fragmentada dos processos de trabalho, com papéis tradicionais bem delimitados, resultaram em maior ou menor possibilidade de construir parcerias no dia-a-dia do trabalho e na "fertilidade" das novas ideias e/ou práticas de saúde. Já as equipes mais recentes proporcionaram maior disposição para experimentações e inovações;

- Contexto das comunidades, com diferenças entre as características dos locais e de seus moradores, bem como entre os determinantes dos processos de saúde-doença e as necessidades de saúde nos territórios, que demandaram atenção e respostas singulares;

- Confusão de papéis - tanto pelas equipes quanto pelos residentes - em decorrência de apoiar apenas duas equipes, diferentemente do número preconizado pelo NASF- Núcleo de Apoio à Saúde da Família ${ }^{13}$ :

"Tive uma rápida experiência em uma equipe de NASF pós residência, em que apoiava 12 equipes - esse número maior marcava o meu lugar como era, de fato, apoio" (Maria).

\section{Gratificação e impacto para a vida e para o trabalho}

Os residentes apontaram, como mais gratificante em suas atuações, o contato direto com a população, o desenvolvimento de projetos e práticas terapêuticas singulares e/ou coletivas, o trabalho em equipe (equipe das USF e equipe de residentes), o aprendizado do respeito aos colegas e a si mesmo, as devolutivas e transformações percebidas em equipes e comunidades, a possibilidade de prevenção de doenças e a atuação "militante" pelo SUS.

"Para mim, o mais gratificante foi (e ainda é) testemunhar transformações. Algumas sutis, delicadas, bonitas de ver acontecer. Transformações na vida de pessoas que conhecemos e acompanhamos no cuidado em saúde. Transformações no trabalho das equipes, ou seja, no meu próprio trabalho. Aos poucos fomos aprendendo a construir frutiferos laços de parceria e de afeto com os trabalhadores de onde estivemos. E isso foi mesmo gratificante.

Também é fonte de satisfação a dimensão de militância que o trabalho na saúde pública/saúde coletiva traz. É por princípios caros que escolhi trabalhar no SUS e é alimentando utopias que sustento esta escolha." (Ana) 
Cinco entrevistados referiram trabalhar como terapeutas ocupacionais no serviço público: em CAPS, ambulatório de geriatria, docência universitária, programas de facilitação de Educação Permanente. Outros dois não estão exercendo a profissão: um atua em outra área enquanto o segundo aguarda convocação de concurso público. De forma unânime, foi referida a relevância da vivência na RMSFC para suas ocupações atuais e para seu desenvolvimento pessoal.

Para estes sujeitos, a residência influenciou na escolha pelo trabalho no SUS e em equipe, na valorização do controle social, de uma clínica ampliada e de uma escuta qualificada; em um trabalho integral, em rede e intersetorial; em práticas de Educação Permanente e de matriciamento.

"Os aprendizados e experiências que ficaram do período de residencia foram e serão sempre muito ricos e aproveitados em qualquer outro contexto de trabalho. Influenciam no olhar, compreensão e manejo de um determinado contexto ou grupo. Influenciam na convivência e discussões com outros profissionais que estejam atuando na resolução de um mesmo problema. (Isis)

\begin{abstract}
"Essa vivência durante a Residência permite que o terapeuta ocupacional chegue mais preparado para o trabalho atual e não necessite aprender esses manejos ao longo de suas atuações". (Helena)
\end{abstract}

\section{CONSIDERAÇÕES FINAIS}

Os concluintes reconheceram que a experiência no PRMSFC foi fundamental para sua formação pessoal e profissional e se sentiram mais preparados para o mercado de trabalho. Observou-se que, embora existam diferenças na experiência, nas diversas competências, todos os residentes puderam vivenciar e reconhecer no campo da Saúde Coletiva, as práticas na Estratégia Saúde da Família de forma ampliada, atendendo aos conceitos desta estratégia.

A diversidade experiencial tem relação com o leque de oportunidades apresentadas nos campos de prática - em decorrência de inserção pessoal e profissional, circulação de afetos, contexto, resistências, compreensão de papéis - quanto à metodologia ativa de ensino-aprendizagem, cuja teorização

\section{REFERÊNCIAS}

1. Brasil. Ministério da Saúde. Secretaria de Atenção à Saúde. Departamento de Atenção Básica. Política foi desenvolvida na e pela prática, com olhares e fazeres singulares de cada residente.

Além disso, no núcleo da Terapia Ocupacional foi possível perceber o desenvolvimento de abordagens de caráter coletivo e territorial para populações em vulnerabilidade, vistas sob um olhar integral. As demandas e/ou problemáticas que mais receberam o olhar dos residentes foram a da Saúde Mental, o acompanhamento do desenvolvimento neuropsicomotor de crianças e adolescentes e a dimensão do Trabalho.

Os egressos reconheceram que há barreiras no PRMSFC relacionadas ao próprio programa, à Rede Escola e ao coletivo dos residentes. Estes fatores, ao mesmo tempo que dificultaram (e alguns consideram até que prejudicaram) a formação, puderam ser encarados como processos que levaram ao amadurecimento e aprendizado no manejo de situações adversas.

Os fatores facilitadores foram relacionados principalmente ao vínculo, acolhimento e trocas entre residentes e destes com usuários e equipes, além do processo pedagógico ativo da residência.

Enfim, os concluintes, sem exceção, valorizaram sua formação como residentes e as experiências que puderam enriquecer sua formação profissional e pessoal conforme os depoimentos que mostram este impacto em suas vidas:

\footnotetext{
"Foram muitas as situações marcantes. Lembro de muitas histórias que ouvi dos usuários, suas próprias histórias, que me marcaram bastante. A confiança que depositavam ao contá-las foi de inestimável valor. Conheci muito da vida a partir de seus testemunhos. E amadureci. Também foram preciosos os incontáveis encontros com os colegas residentes: as discussões políticas, as construções do trabalho e as amizades." (Ana) "Em uma reunião de saúde com a comunidade, um
senhor que, quase sempre participava, mas quase nunca
se pronunciava, pediu a palavra e disse emocionado,
mais ou menos assim: 'Vivo nesta cidade há mais de 50
anos, e nunca tinha visto pessoas com tanta vontade de
cuidar das pessoas do nosso bairro. A gente sabe que é
muito problema pra resolver e que vocês são poucos.
São poucos, mas são muitos pra gente aqui. Eu me
sinto seguro nesta unidade de saúde'. E todos bateram
palmas!" (Carlos).
}

Nacional de Atenção Básica. Brasília; 2012.

2. Campos GWS, Gutierrez AC, Guerrero AVP, Cunha GT. 
Reflexões sobre a atenção básica e a estratégia de saúde da família. In: Campos GWS, Guerrero AVP. Manual de práticas de atenção básica: saúde ampliada e compartilhada. São Paulo: Aderaldo \& Rothschild; 2008.

3. Barros DD, Ghirardi MI, Lopes RE. Terapia ocupacional social. Rev Ter Ocup Univ São Paulo. 2002;13(3):95-103. doi: http://dx.doi.org/10.11606/issn.2238-6149.v13i3p95-103.

4. Brasil. Ministério da Saúde. Programa Nacional de Melhoria do Acesso e da Qualidade da Atenção Básica. Brasília; 2011.

5. Campos GWS, Domitti A C. Apoio matricial e equipe de referência: uma metodologia para gestão do trabalho interdisciplinar em saúde. Cad Saude Publica, Rio de Janeiro. 2007;23(2): 399-407. http://dx.doi.org/10.1590/S0102$311 X 2007000200016$

6. Brasil. Ministério da Saúde. Secretaria de Gestão do Trabalho e Educação na Saúde. Departamento de Gestão da Educação na Saúde. Residência multiprofissional em saúde: experiências, avanços e desafios. Brasília, DF; 2006.

7. Campos GWS. Saúde pública e saúde coletiva: campo e núcleo de saberes e práticas. Sociedade Cultura. 2000;3(1,2):51-74.

8. UFSCAR/SÃO CARLOS. Manual da residência multiprofissional em saúde da família e comunidade 20102012. São Carlos: EdUFSCar; 2010

9. Nicolaci-da-Costa AM, Romao-Dias D, Di Luccio F. Uso de entrevistas on-line no método de explicitação do discurso subjacente (MEDS). Psicol Reflex Crit, Porto Alegre. 2009;22(1):36-43. http://dx.doi.org/10.1590/S010279722009000100006 .

Recebido para publicação: 17/06/2013

Aceito para publicação: 25/11/2013
10. Minayo MCS. O desafio do conhecimento: pesquisa qualitativa em saúde. 9a ed. São Paulo: Hucitec; 2006.

11. Malfitano APS. Campos e núcleos de intervenção na terapia ocupacional social. Rev Ter. Ocup Univ São Paulo, Brasil. 2005;16(1):1-8. doi: http://dx.doi.org/10.11606/issn.22386149.v16i1p1-8.

12. Soares LBT. A terapia ocupacional na atenção básica no município de São Carlos: a residência multiprofissional em saúde da família e comunidade antecipa os núcleos de apoio à saúde da família. Rev Ter Ocup Univ São Paulo, Brasil. 2008;19:169-72.

13. Brasil. Ministério da Saúde. Portaria 154, de 24 de janeiro de 2008 [citado 18 set. 2010].. Disponível em: http://duvas. saude.pi.gov.br/sistemas_de_informacao/doc_tec_leg/siab/ portaria-n-154-nasf.pdf.

14. Rosa SD, Lopes RE. Política de formação profissional: o caso da residência multiprofissional em saúde. Quaestio Rev Est Educ, Sorocaba. 2011;13:13-23. Disponível em: http:// periodicos.uniso.br/ojs/index.php?journal $=$ quaestio\&page $=\mathrm{a}$ rticle\&op=view\&path $\% 5 \mathrm{~B} \% 5 \mathrm{D}=205$.

15. Barban EG, Oliveira AA. O modelo de assistência da equipe matricial de saúde mental no Programa Saúde da Família do município de São José do Rio Preto (Capacitação e educação permanente aos profissionais de saúde na atenção básica). Arq Cienc Saúde. 2007,14(1):52-63. Disponível em: http://www. cienciasdasaude.famerp.br/racs_ol/vol-14-1/ID224.pdf 